\title{
A review of the Delia interflua group with descriptions of two new species (Diptera, Anthomyiidae)
}

\author{
Jing Du', Wanqi Xue ${ }^{2}$ \\ I College of Life Science, Shenyang Normal University, Shenyang 110034, China 2 Institute of Entomology, \\ Shenyang Normal University, Shenyang 110034, China \\ Corresponding author: Wanqi Xue (xwqfly@sina.com)
}

Academic editor: P. Cerretti | Received 4 December 2017 | Accepted 5 May 2018 | Published 5 June 2018

http://zoobank.org/B4EAEBA0-AB27-4687-922D-52EAC361817D

Citation: Du J, Xue W (2018) A review of the Delia interflua group with descriptions of two new species (Diptera, Anthomyiidae). ZooKeys 764: 145-154. https://doi.org/10.3897/zookeys.764.22736

\begin{abstract}
The Delia interflua group is reviewed to include 16 species. Two new species are described, namely Delia subnemostylata Xue \& Du, sp. n., Delia nigeriposticrus Xue \& Du, sp. n. A catalogue and amended key to new species of this group are also included.
\end{abstract}

\section{Keywords}

Anthomyiidae, Delia, key, new species

\section{Introduction}

The genus Delia Robineau-Desvoidy, 1830 belongs to the dipteran family Anthomyiidae. More than 310 species in this genus (excluding Neotropical species) are known from around the world (Hennig1974, Ackland and Pont 1977, Fan et al. 1988, Pont 1989, Griffiths 1991, Dely-Draskovits 1993, Wei et al. 1996, Ackland 2008, Xue and Du 2008, Xue and Du 2009, Wang et al. 2014, Du and Xue 2017). The Delia interflua group is a small group and can be recognized by the following characters: the apices of the sternite $\mathrm{V}$ processes dilate and rounded, except for D. subnemostylata sp. n.; cercal 
plate with long setae; surstyli elongated, except for D. kullensis; usually the acrophallus is supported by a sclerotized bridge between the bases of the free paraphallic processes; the sclerotized bridge is prolonged downwards, forming a membranous process (Griffiths 1991, Xue and Du 2008). In this work, two new species of this group are described, Delia subnemostylata Xue \& Du, sp. n., Delia nigeriposticrus Xue \& Du, sp. n. The key produced by Wei et al. (1996) is here modified to include three couplets leading to the identification of the new species.

\section{Materials and methods}

All specimens were collected from Yunnan province of China. Type specimens are deposited in the Diptera collection of the Institute of Entomology, Shenyang Normal University (IESNU). They were examined under an Olympus SZ-ST stereomicroscope. Morphological terminology is based mainly on that of McAlpine (1981). Abbreviations for terms used in this study are:

$\begin{array}{llll}a & \text { anterior setae; } & \text { pd } & \text { posterodorsal setae; } \\ a c r & \text { acrostichal setae; } & \text { post acr } & \text { postsutural acrostichal setae; } \\ a d & \text { anterodorsal setae; } & \text { post } d c & \text { postsuturaldorsocentral setae; } \\ a v & \text { anteroventral setae; } & \text { pra } & \text { prealar setae; } \\ d & \text { dorsal setae; } & \text { prst acr } & \text { presutural acrostichal setae; } \\ d c & \text { dorsocentral setae; } & \text { prst } d c & \text { presutural dorsocentral setae; } \\ i a l & \text { intra-alar setae; } & p v & \text { posteroventral setae; and } \\ p & \text { posterior setae; } & \mathrm{R}_{4+5} & \text { branch of radius. }\end{array}$

Addendum to the key by Wei et al. (1996) for the new species of the Delia interflua group (males)

7a Hind tibia with 2 rows of $p v$

D. duplicipectina Fan in Fan \& Zheng, 1993

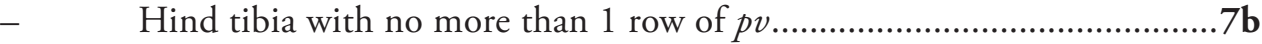

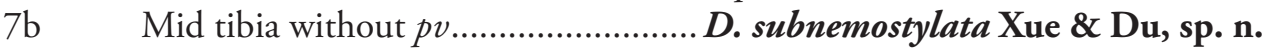

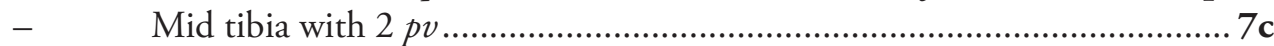

7c Hind tibia with $2-3 a v, 5 a d, 5-7 p d$ and $5 p v$

D. nemostylata Deng \& Li, 1984

- $\quad$ Hind tibia with a row of $a v$ (approx. 9-10), a row of ad (approx. 7-8), a row of $p d$ (3 strong) and a complete row of $p v$ 


\section{Taxonomy}

Delia subnemostylata Xue \& Du, sp. n. http://zoobank.org/7B62520A-3712-4E81-83CE-A71C0897DFED Figure 1

Type material. Holotype. China, Yunnan Province, Baimang Snowberg, 38004200 m, 5 July 2006, Mingfu Wang Co., ô (IESNU). Paratype. China, same data as holotype, $3 \hat{\jmath} \widehat{\jmath}$.

Diagnosis. Frontal setae 4-5 pairs, pra approx. 1.2 times as long as posterior notopleural seta; sternite I with dense long fringes, sternite III with dense long setae; postgonite without setae.

Description. Holotype male. Body length $5.5 \mathrm{~mm}$.

Head. Eyes only with several short ciliae in lower margin; frontal vitta red brown in lower part, remaining black, 2.0 times as wide as fronto-orbital plate; frons 1.5-2.0 times as wide as anterior ocellus; frontal vitta with a pair of inter frontal setae; without orbital setae; frontal setae 4-5 pairs, situated on lower half; fronto-orbital plate, parafacial with dark gray tomentum, parafacial 1.3 times as wide as postpedicel; antenna black, postpedicel 2.0-2.3 times as long as broad; arista pubescent, the longest aristal hairs shorter than its basal diameter; lower facial margin not projecting, vibrissal angle and frontal angle in the same vertical plane in profile; gena sparsely with dark gray tomentum, genal height approx. 1/4 of eye height; anterior margin of gena with two rows of upcurved subvibrissal setulae; postocular setae extending to ventral surface, epicephalon haired; proboscis short, prementum with gray tomentum sparsely, 2.5 times as long as broad, palpus black, equal to the length of prementum.

Thorax. Ground color black with fuscous tomentum; scutum with three distinct black vittae; with two rows of hair-like prstacr, only one pair of post acr distinctly in front of scutoscutellar suture, $d c 2+3$, ial $0+2$; without outer posthumeral seta; pra approx. 1.2 times as long as posterior notopleural seta; scutellum without spots, lower surface with some pale hairs apically; anterior anepisternal setae absent; notopleuron haired; basisternum of prosternum, anepimeron, meron and katepimeron all bare; both anterior and posterior spiracles small and fuscous; katepisternal seta $1+2$.

Wing. Base brown and basicosta fuscous; costa setulose only basally on ventral surface, anterior surface with a row of pectinated spines; costal spine subequal to crossvein $\mathrm{r}-\mathrm{m}$; radial node bare, calypters yellowish, lower calypter approx. 2/5 length of upper one; halter yellow.

Legs. Entirely black; fore tibia with 1 submedial $a d$ and 1 medial $p$; mid femur without distinct $a v$, with $4-5$ strong $p v$ in basal half; mid tibia with 1 submedial $a v, 1 p d$ and 1 preapical $p$, without $p v$; mid tarsomere 1 without distinct setae; hind femur with 7-8 av in distal 2/3 (2 strong), only with distinct $p v$ in distal part; hind tibia with $3 a v, 2 a d, 3 p d$, and 4-5 $p v$; all tarsi shorter than tibiae, claws and pulvilli shorter than tarsomere 5 . 


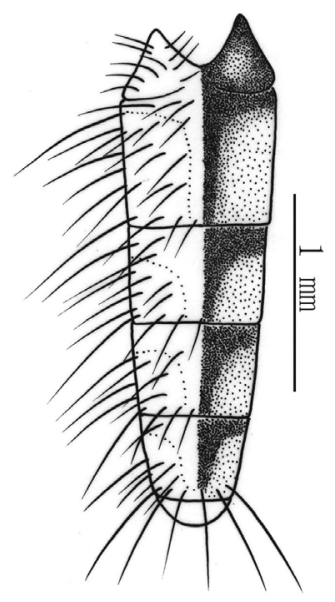

A

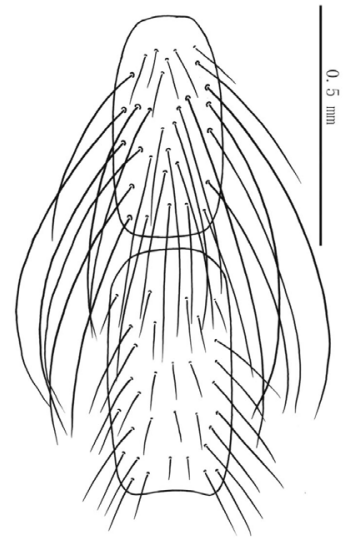

B

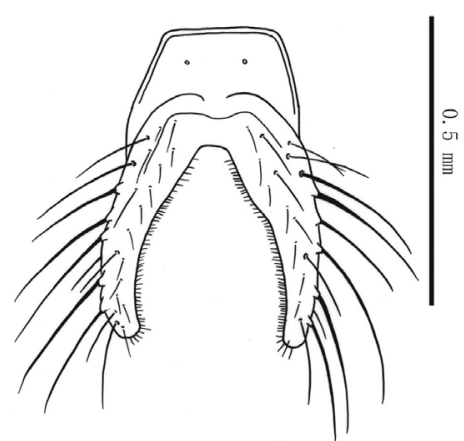

C

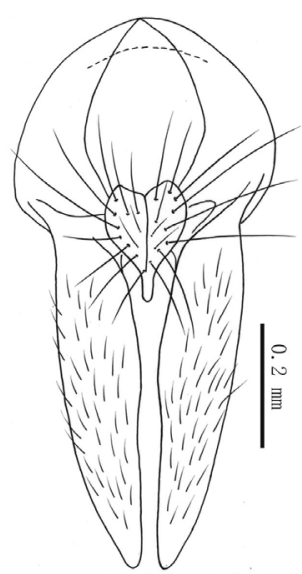

D

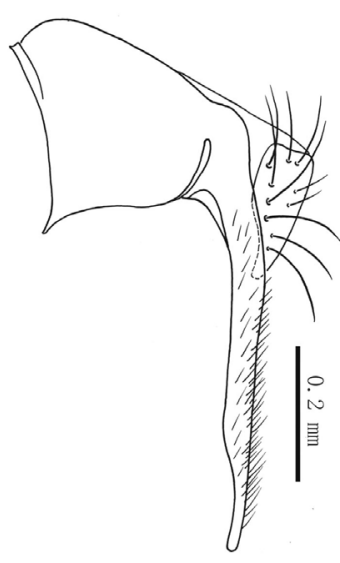

E

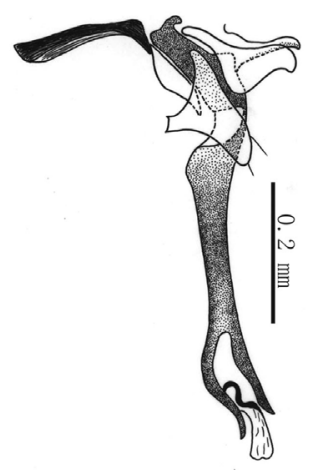

F

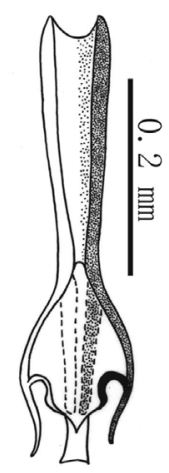

G

Figure I. Delia subnemostylata Xue \& Du, sp. n. (male). A Abdomen in dorsal view B Sternites III and IV in ventral view $\mathbf{C}$ Sternite V in ventral view $\mathbf{D}$ Epandrium, cerci, and surstyli in posterior view $\mathbf{E}$ Ditto, left lateral view $\mathbf{F}$ The hypandrial complex in left lateral view $\mathbf{G}$. Distiphallus in anterior view.

Abdomen. Black, long flat-shaped(Fig. 1A); tergite 2 slightly longer; all tergites with T-shaped spots, lateral setae and posterior marginal setae developed, tergite VI bare; sternite I with dense and long fringes, sternite III with dense and long setae (Fig. 1B); sternite IV with short setae; sternite $\mathrm{V}$ processes (Fig. 1C) longer than base; cercal plate (Fig. 1D) 1.2 times longer than wide, heart-shaped, apex finger-shaped, bearing a few short setae; surstyli 3.0 times length of cercal plate, in lateral view (Fig. 1E) slender; pregonite with two setae, postgonite without setae. Aedeagus as illustrated in Figure 1F, G; acrophallus longitudinally directed, supported by a sclerotized bridge 
between the bases of the free paraphallic processes, the sclerotized bridge is prolonged downwards, forming a membranous process.

Female. Unknown.

Remarks. This new species is similar to D. nemostylata Deng \& Li, 1984 as it has very similar genitalia, but differs from it for its frontal setae 4-5 pairs, katepisternal seta $1+2$; lower calypter approx. 2/5 length of upper one; fore tibia with one submedial ad and one medial $p$; mid tibia without $p v$; hind tibia with two ad and three $p d$.

Etymology. This new species is similar to D. nemostylata Deng \& Li, 1984. Hence, its epithet is derived to reflect this relationship.

Distribution. China, Yunnan Province (Baimang Snowberg).

\section{Delia nigeriposticrus Xue \& Du, sp. n.}

http://zoobank.org/7EC8D21A-C593-4267-9FF6-2EE7691A547C

Figure 2

Type material. Holotype. China, Yunnan Province, Yulong Snowberg, Big ropeway,4571 m, 29 June 2006, Mingfu Wang Co., ठ̊(IESNU). Paratype. China, same data as holotype, $2 \hat{\jmath} \widehat{\jmath}$.

Diagnosis. Frontal vitta almost absent at the narrowest part; pra longer than posterior notopleural seta; both mid femur and hind femur with complete rows of $a v$ and $p v$; sternites $\mathrm{V}$ processes with expanded tips, without blunt apical setae; postgonite without setae.

Description. Holotype male. Body length 5.0-5.2 $\mathrm{mm}$.

Head. Eye bare; frontal vitta black, line form at the narrowest part; frons as wide as anterior ocellus; frontal vitta with 2 pairs of interfrontal setae; without orbital setae; 7 pairs of frontal setae, situated on lower half of frons; fronto-orbital plate and parafacial with fuscous tomentum; parafacial 1.2 times wider than postpedicel; antenna black, postpedicel 1.5-2.0 times longer than broad; arista pubscent, the longest hair shorter than its basal diameter; vibrissal angle situated behind frontal angle in profile; genal height approx. 1/4 eye height; anterior margin of gena with 2 rows of upcurved subvibrissal setulae; postocular setae extending to ventral surface, epicephalon bare; prementum mostly with gray tomentum, 5.0 times longer than broad; palpus short and black, not more than half length of prementum.

Thorax. Black in ground color with brown-gray tomentum; scutum with 3 black vittae, extended to scutoscutellar suture; two rows of hair-like prstacr, only a single pair of post acr developed, $d c 2+3$, ial $0+2$; one pair of weak outer posthumeral setae; pra longer than posterior notopleural seta; scutellum without spots, ventral margins with some pale setae apically; anterior anepisternal setae absent; notopleuron, basisternum of prosternum, anepimeron, meron, and katepimeron bare; both anterior and posterior spiracles small and fuscous; katepisternal seta $1+2$.

Wing. Base fuscous, basicosta black; costa setulose only basally on ventral surface; costal spine short; radial node bare, calypters brown yellow; lower calypter approx. 1/3 length of upper one; halter yellow. 


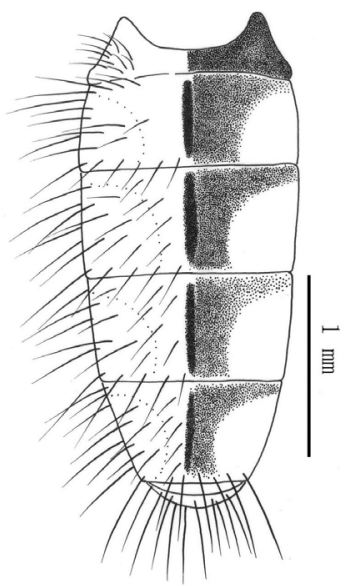

A

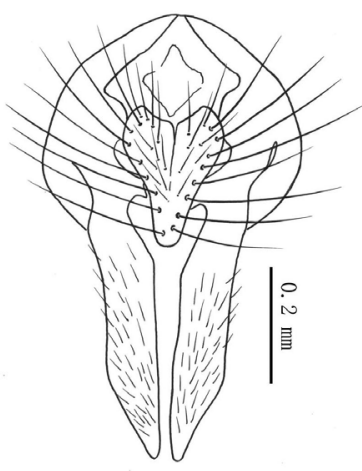

D

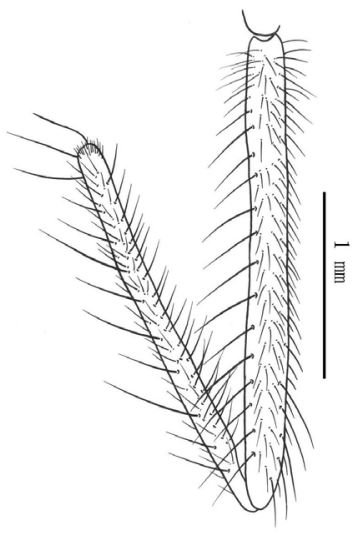

B

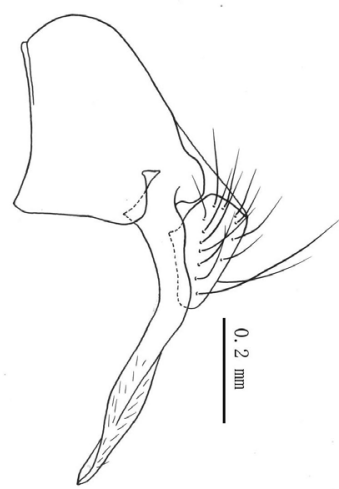

E

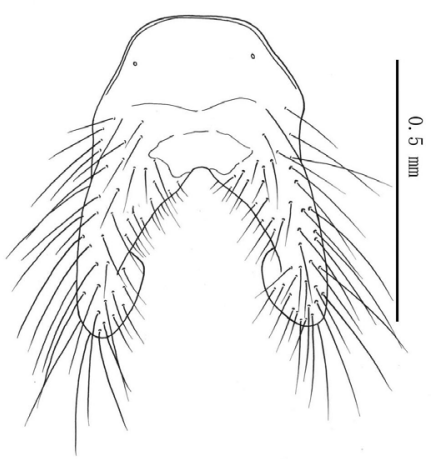

C

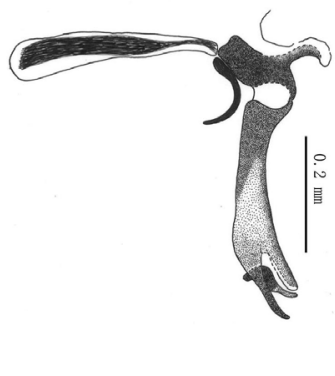

F

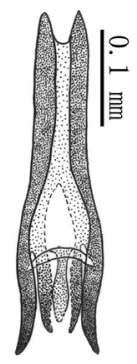

G

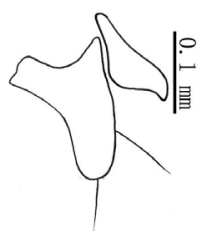

$\mathrm{H}$

Figure 2. Delia nigeriposticrus Xue $\&$ Du, sp. n. (male). A Abdomen in dorsal view B Hind femur and tibia in posterior view $\mathbf{C}$ Sternite $\mathrm{V}$ in ventral view $\mathbf{D}$ Epandrium, cerci, and surstyli in posterior view $\mathbf{E}$ Ditto, left lateral view $\mathbf{F}$ The hypandrial complex in left lateral view $\mathbf{G}$ Distiphallus in anterior view $\mathbf{H}$ Gonites. 
Legs. Entirely black; fore tibia with single medial $p$; mid femur with a complete row of $a v$, becoming shorter apically, a complete row of long and dense $p v$, becoming longer mediately, 1.8 times as long as its diameter, $1-2$ preapical $p d$;mid tibia with one super-medial $p d$ and two $p v$; hind femur with complete rows of $a v$ and $p v$, becoming longer apically; hind tibia with a row of av (approx. 9-10), a row of ad (approx. 7-8), a row of $p d$ (three strong) and a complete row of $p v$, becoming shorter apically; fore tarsus longer than tibia, all claws and pulvilli longer than tarsomere 5.

Abdomen. Black, long flat-shapes in dorsal view (Fig. 2A); all tergites with narrow black vittae in center, lateral surface with dark brown allochroic spot, outer lateral surface with gray tomentum; tergite VI bare; sternite I with dense hairs; sternites V processes with expanded tips. Cercal plate (Fig. 2D) 1.2 times longer than wide, heartshaped, with narrowly rounded apex; surstyli 2.5 times length of cercal plate, in lateral view (Fig. 2E) strongly bent in basal half; pregonite (Fig. 2H) with 2 setae, postgonite without setae. Aedeagus as Fig. 2F-2G; acrophallus longitudinally directed, supported by a sclerotized bridge between the bases of the free paraphallic processes, the sclerotized bridge is prolonged downwards, forming a membranous process.

Female. Unknown.

Remarks. This new species is similar to D. fulviposticrus Li \& Deng, 1981 as it has very similar genitalia, but differs from it for its male body length $5.0-5.2 \mathrm{~mm}$; frontal vitta black; prementum 5.0 times longer than broad; legs black; mid femur with a complete row of $a v$, becoming shorter apically, a complete row of long and dense $p v$, becoming longer medially, 1.8 times as long as its diameter, 1-2 preapical $p d$; hind femur with a complete row of $p v$, becoming longer apically.

Etymology. The specific name is from the Latin word niger, black, referring to its legs being entirely black which differs from those of Delia fulviposticrus Li \& Deng, 1981 which are yellow legs.

Distribution. China, Yunnan Province (Yulong Snowberg).

\section{Catalogue of the known species in the Delia interflua group}

\section{Delia absidata Xue \& Du, 2008}

Delia absidata Xue \& Du, 2008. Type locality: China: Yunnan, Shangri-la.

Distribution. China: Yunnan Province, Shangri-la, Bitahai.

\section{D. abstracta (Huckett, 1965)}

Hylemya (Delia) abstracta Huckett, 1965. Type locality: Canada: North-West Territories.

Distribution. Canada; Mongolia.

\section{Delia brevipalpis Xue \& Zhang, 1996}

Delia brevipalpis Xue \& Zhang, 1996. Type locality: China: Qinghai, Hoh Xil.

Distribution. China: Qinghai, Hoh Xil.

Note. According to type species, both pregonite and postgonite without setae. 


\section{Delia conjugata Deng \& Li, 1994}

Delia conjugata Deng \& Li, 1994. Type locality: China: Sichuan, Emeishan.

Distribution. China: Sichuan, Emeishan.

Note. This species is very similar to $D$. stenostyla, but sternites $\mathrm{V}$ processes with narrowly rounded apices, without expanded tips; cercal plate more narrower, with a pair of long distal setae; surstyli in caudal view not expanded medially.

\section{Delia duplicipectina Fan in Fan \& Zheng, 1993}

Delia duplicipectina Fan, 1993. Type locality: China: Sichuan, Xiangcheng.

Distribution. China: Sichuan, Xiangcheng.

Note. According to type species description, the sternite $\mathrm{V}$ processes have broadly rounded apices, without expanded tips.

\section{Delia fulviposticrus Li \& Deng, 1981}

Delia fulviposticrus Li \& Deng, 1981. Type locality: China: Sichuan, Emeishan.

Distribution. China: Sichuan, Emeishan.

\section{Delia interflua (Pandellé, 1900)}

Chortophila interflua Pandellé, 1900. Type locality: France: Hautes-Pyrénées, Arrens.

Chortophila flavisquama Stein, 1916. Type localities: Germany: Treptow; Austria: Insbruck; Sweden.

Chortophila setitibia Stein, 1916. Type localities: Yugoslavia: Istria; Austria: Schneeberg in Krain.

Hylemyia latifasciata Ringdahl, 1926. Type locality: Sweden: Jämtland.

Delia karasawana Suwa, 1974. Type locality: Japan: Honshû, Nagano-ken, Mt. Hodaka. Distribution. China (Sichuan, Qinghai); Austria; Switzerland; The Czech Republic; Slovakia; Germany; France; Great Britain; Hungary; Italy; Poland; Sweden.

\section{D. kullensis (Ringdahl, 1933)}

Hylemya (Delia) kullensis Ringdahl, 1933. Type locality: Sweden: "Kullaberg in Schonen".

Distribution. Sweden; Czech Republic; Slovakia.

\section{D. kumatai Suwa, 1977}

Delia kumatai Suwa, 1977. Type locality: Nepal: Bangel Kharka.

Distribution. Nepal.

\section{Delia nemostylata Deng \& Li, 1984}

Delia nemostylata Deng \& Li, 1984. Type locality: China: Sichuan, Emeishan.

Distribution. China: Sichuan, Emeishan.

\section{Delia pansibirta Jin \& Fan in Jin et al. 1981}

Delia pansibirta Jin \& Fan, 1981. Type locality: China: Gansu, Wenxian. 
Distribution. China: Gansu, Wenxian.

Note. A body covered with more hair is a characteristic that distinguishes this species from other species of this species group.

\section{Delia spicularis Fan in Fan et al. 1984}

Delia spicularis Fan, 1984. Type locality: China: Qinghai, Yushu.

Distribution. China: Qinghai, Yushu.

\section{Delia stenostyla Deng \& Li, 1994}

Delia stenostyla Deng \& Li, 1994. Type localities: China: Sichuan, Emeishan; Songpan; Maowen.

Distribution. China: Sichuan, Emeishan; Songpan and Maowen.

\section{Delia subinterflua Xue \& Du, 2008}

Delia subinterflua Xue \& Du, 2008. Type localities: China: Sichuan, Balangshan; Yunnan, Yulong Snowberg and Baimang Snowberg.

Distribution. China: Yunnan Province, Mt. Yulong, Big Ropeway; Sichuan, Mt. Balang.

\section{Acknowledgements}

This paper was supported by the National Natural Science Foundation of China (No. 31401990). Thanks are due to Mingfu Wang for providing the examined material.

\section{References}

Ackland DM, Pont AC (1977) Family Anthomyiidae. In: Delfinado MD, Hardy DE (Eds) A Catalog of Diptera of the Oriental Region, Volume III. The University Press of Hawaii, Honolulu, 441 pp.

Ackland DM (2008) Revision of Afrotropical Delia Robineau-Desvoidy, 1830 (Diptera: Anthomyiidae), with descriptions of six new species. African Invertebrates 49(1): 1-75. https://doi.org/10.5733/afin.049.0101

Dely-Draskovits Á (1993) Family Anthomyiidae. In: Soós Á, Papp L (Eds) Catalogue of Palaearctic Diptera. Akadémiai Kiadó, Budapest 13: 37-51.

Deng AX, Li R (1984) Description of the Delia nemostylata sp. nov.. Sichuan Journal of Zoology 3: 5-6. [in Chinese with English summary]

Deng AX, Li R (1994) Descriptions of Three New Species of the Genus Delia, Anthomyiidae, Diptera in Sichuan, China. Journal of West China University of Medical Sciences 25: 18-21. [In Chinese with English summary]

Du J, Xue WQ (2017) Four new species of the genus Delia Robineau-Desvoidyin the Yunnan Province of China (Diptera, Anthomyiidae). ZooKeys 693: 141-153. https://doi. org/10.3897/zookeys.693.12965 
Fan ZD, Chen ZZ, Ma SY, Wu Y (1984) New species of the family Anthomyiidae (Diptera) from Qinghai Province, China, I. Contributions from Shanghai Institute of Entomology 4: 239-253. [In Chinese with English summary]

Fan ZD, Sun CH, Chen ZZ, Ma SY, Wu L, Ge FX, Xue WQ, Cui CY, Wang CS, Ma CY, Wang CJ, Jin ZY, Jiang TJ, Qian JQ, Li R (1988) Diptera: Anthomyiidae. EconomicInsect Fauna of China 37. Science Press, Beijing, China, 144-189. [In Chinese with English summary] Fan ZD, Zheng SS (1993) Anthomyiidae. In: Chen SX (Ed.) Insects of the Hengduan Mountains Region 2. Science Press, Beijing, 1127-1165. [In Chinese with English summary]

Griffiths GCD (1991) Anthomyiidae [part]. In: Lindner E (Ed.) Flies of the Nearctic Region 8(2) 7-10. E. Schweizerbart, Stuttgart, 953-1632.

Hennig W (1974) Anthomyiidae. In: Lindner E (Ed.) Die Fliegen der Palaearktischen Region 63a. Schweizerbart, Stuttgart, 687-920.

Huckett HC (1965) The Muscidae of Northern Canada, Alaska, and Greenland (Diptera). Memoirs of the Entomological Society of Canada 42: 36-73. https://doi.org/10.4039/entm9742fv Li R, Deng AX (1981) Notes on Anthomyiidae from mountain Emei, China, I. Description of 5 species. Acta Academiae Medicinae Sichuan 12: 125-131. [In Chinese with English summary] Jin ZY, Ge FX, Fan ZD (1981) Descriptions of five new species of Anthomyiidae from south Gansu, China (Diptera). Entomotaxonomia 3: 87-92. [In Chinese with English summary] McAlpine JF (1981) Morphology and terminology - adults. In: McAlpine JF, Peterson BV, Shewell GE, Teskey HJ, Vockeroth JR, Wood DM (Eds) Manual of Nearctic Diptera. Volume I. Agriculture Canada Monograph 27: 9-63.

Pandellé L (1900) Études sur les Muscides de France. III ${ }^{e}$ partie. Revue d'Entomologie. Caen 19 (spec. pagination): 262 [cont.].

Pont AC (1989) Family Anthomyiidae. In: Neal LE (Ed.) Catalog of the Diptera of the Australasian and Oceanian regions. (Bishop Museum Special Publication 86). Bishop Museum Press and E. J. Brill, Honolulu, 674 pp.

Ringdahl O (1933) Översikt av i Sverige funna Hylemyia-arter. Entomologisk Tidskfirt 54: 1-35. Robineau-Desvoidy JB (1830) Essai sur les Myodaires. Mémoires présentés par divers savants à l'Académie Royale des Sciences de l' Institut de France 2: 482.

Suwa M (1977) Anthomyiidae collected by the Hokkaido University Expeditions to Nepal Himalaya, 1968 and 1975 (Diptera). Insecta Matsumurana 10: 17-51.

Wang MM, Michelsen V, Li K, Zhu WB (2014) Supplementary catalogue of the Anthomyiidae (Diptera) of China. ZooKeys 453: 71-109. https://doi.org/10.3897/zookeys.453.8282

Wei LM, Xue WQ, Cui CY (1996) The family Anthomyiidae of China (Diptera). In: Xue WQ, Chao CM (Eds) Flies of China. Volume 1. Liaoning Science and Technology Press, Shenyang, 706-724. [In Chinese with English summary]

Xue WQ, Du J (2008)Two new species of Delia, with a key to the males of the world species of the interflua group (Diptera: Anthomyiidae). Entomological News 119(2): 113-122. https://doi.org/10.3157/0013-872X(2008)119[113:TNSODW]2.0.CO;2

Xue WQ, Du J (2009) A study of the world species of the Delia alaba subsection, with descriptions of two new species (Diptera: Anthomyiidae). Entomologica Americana 115(2): 154-159.

Xue WQ, Zhang XZ (1996) Anthomyiidae. In: Wu SG, Feng ZJ (Eds) The Biology and Human Physiology in the Hoh Xil Region. Science Press, Beijing, 167-191. [In Chinese with English summary] 